\title{
Ampliar reflexóes e alternativas: análise de moradias para pessoas com transtorno mental grave no Brasil
}

I ${ }^{1}$ Wagner Yoshizaki Oda, ${ }^{2}$ Adriana Pinheiro Carvalho, ${ }^{3}$ Carla Mara Hilário, ${ }^{4}$ Juarez Pereira Furtado I

Resumo: Partindo do pressuposto de que haveria no plano teórico certa correspondência à estagnação numérica e qualitativa de opçóes e ofertas de moradia voltadas às pessoas com transtornos mentais graves no Brasil, analisamos, por meio de revisão bibliográfica e bibliometria, como o tema vem sendo abordado em publicaçóes nacionais indexadas nas bases Lilacs e Scopus, entre os anos 2000 e 2017. Constatamos que a distribuição regional brasileira dos autores é desigual e a produção científica ainda é numericamente limitada, predominantemente descritiva e focada nos processos de trabalho e suporte. Os desenhos metodológicos variam pouco e os referenciais teóricos são oriundos de textos seminais que embasaram o início da reforma psiquiátrica brasileira. Entendemos que os achados deste estudo permitem confirmar o pressuposto inicial de que o debate acerca da moradia para pessoas com transtornos mentais graves carece de novas abordagens teóricas e metodológicas, ao contrário do que indicam normativas recém-divulgadas pelo Ministério da Saúde nesse sentido.

> Palavras-chave: desinstitucionalização; saúde mental; habitação; indicadores bibliométricos.

\author{
1 Programa de Pós-Graduação em \\ Saúde Coletiva, Universidade de \\ São Paulo. São Paulo-SP, Brasil \\ (wagner.oda@gmail.com). \\ ORCID: 0000-0002-3043-6396 \\ 2 Departamento de Saúde Coletiva, \\ Universidade de São Paulo. \\ São Paulo-SP, Brasil (adriana. \\ pinheirocarvalho@gmail.com). \\ ORCID: 0000-0001-9548-0577 \\ ${ }^{3}$ Departamento de Ciência da \\ Informação, Universidade Estadual \\ de Londrina. Londrina-PR, Brasil \\ (hilariopesquisa@gmail.com). \\ ORCID: 0000-0002-2464-1502 \\ ${ }^{4}$ Departamento de Políticas \\ Públicas e Saúde Coletiva, \\ Universidade Federal de São \\ Paulo. São Paulo-SP, Brasil \\ (juarezpfurtado@gmail.com) \\ ORCID: 0000-0001-6605-1925
}

Recebido em: 19/11/2019 Aprovado em: 03/02/2020 Revisado em: 24/03/2021 


\section{Introdução}

A garantia de moradia para pessoas com transtornos mentais graves (TMG) constitui desafio para os países que implementaram processos de desinstitucionalização psiquiátrica nas últimas décadas (WHO, 1993). Nos Estados Unidos, Inglaterra, França e Canadá, as alternativas de moradia para pessoas com longo tempo de internação foram propostas, nos anos 1950 e 1960 (NELSON, 2010). Experiências mais recentes, em alguns desses países citados, definiram modelos com diferentes níveis de suporte como respostas mais adequadas às necessidades das pessoas com TMG, evitando reinternações e tentativas de suicídio (LEFF et al., 2009). Dessa forma, ampla gama de modelos foi estabelecida, combinando distintamente aspectos como o tempo em que os pacientes podem permanecer residindo, nível de funcionalidade dos moradores, oferta ou não de tratamento, compartilhamento ou não das acomodaçóes, residências espalhadas pela cidade ou agrupadas em dado local, dentre outros (SISKIND et al., 2013). O aperfeiçoamento dos modelos de apoio à moradia para essa clientela tem se baseado na modulação entre tratamento e moradia (FURTADO, 2014), observando a intensidade dos serviços de reabilitação oferecidos e buscando horizonte de progressáo dos moradores para ambientes menos restritivos e até com plena separação entre o local de moradia e aqueles destinados ao tratamento.

No Brasil, a partir dos anos 1990, houve significativa transformação no modelo assistencial, com redução do número de leitos em hospitais psiquiátricos e criação de redes de serviço substitutivos (TENÓRIO, 2002). Inspirados em experiências nacionais desenvolvidas na década de 1990 (FURTADO; PACHECO, 1998; GUIMARÃES; SAEKI, 2001; GUILHERMANO NETO; OLIVEIRA, 2003), os Serviços Residenciais Terapêuticos (SRT) foram implementados no Sistema Único de Saúde (SUS), no ano 2000, constituindo-se como casas inseridas em meio comunitário, para responder ao conjunto de necessidades decorrentes da saída dos hospitais. Tais serviços apresentam-se em duas modalidades, diferenciando-se quanto ao número de moradores e a intensidade do suporte ofertado (BRASIL, 2004, 2011).

Dezoito anos depois da publicação da portaria ministerial que regulamentou os SRT (BRASIL, 2004), praticamente a única alternativa amplamente implantada no país, a quantidade dos mesmos ainda não contemplou a demanda. Apesar de não haver dados atualizados sobre a quantidade de SRT necessária para a desinstitucionalização de todos os moradores de hospitais psiquiátricos, pode-se ilustrar o descompasso 
entre oferta e demanda ao considerar o censo realizado no Estado de São Paulo e publicado no ano de 2014 (CAYRES et al., 2014), que revelou 4.439 moradores de hospitais psiquiátricos no estado. Por seu turno, dados do Ministério da Saúde apontam 157 unidades do tipo I e 237 unidades do tipo II em 2018 (DATASUS, 2019), abrigando cerca de 3.626 pessoas. Ou seja, somente no estado de São Paulo há mais pessoas aguardando alternativas de moradia do que todos os atuais moradores de SRT no país. Aliado a este fato, temos um ritmo decrescente do número de unidades habilitadas pelo Ministério da Saúde, a partir de 2015, quando foram implantadas 87 unidades, sendo que em 2018 implantou-se 55 unidades (DATASUS, 2019).

O leque de possibilidades de moradia presente nos países centrais citados, que inclui residências de longa permanência, residências de permanência limitada, acomodaçôes para pessoas em situação de rua com TMG, acomodaçóes residenciais para períodos de crise, entre outros (BARBATO et al., 2017), contrasta com a escassez de opçóes para a mesma clientela no Brasil. Cabe ressaltar que, em que pese a normatização dos SRT permitir alguma flexibilidade em sua condução, estudo realizado por Furtado e Nakamura (2014), em cidades de três estados brasileiros, demonstrou pequena variação no modo de funcionamento dos mesmos.

Além dos internos de longa duração, foco dos SRT, há que se considerar a demanda de pessoas com TMG atendidas pelos outros pontos da Rede de Atençáo Psicossocial (RAPS). Parte dessa clientela mora de variadas maneiras (FURTADO; NAKAMURA, 2014), evidenciando, por meio de suas trajetórias (que incluem experiências criativas e outras dramáticas, como a situação de rua), a premente necessidade de ampliação não só quantitativa, mas também qualitativa das formas de apoio à moradia. Por isso, vem somar-se à carência de novos SRT, a necessidade de ampliação das opçóes de moradia a distintas clientelas.

Nesse contexto, nos parece pertinente analisar, de forma sistemática, como a moradia, um dos pilares que assegura efetiva reinserção e permanência de pessoas com TMG na comunidade, vem sendo abordada e discutida, no âmbito da reforma da assistência em Saúde Mental no Brasil. Para isso, abordaremos a produção científica nacional sobre o tema, por meio de revisão bibliográfica, estudo bibliométrico das autorias e coautorias e identificação dos principais referenciais teóricos utilizados. Constitui pressuposto deste estudo que à estagnação numérica e qualitativa de intervençôes dirigidas às moradias de pessoas com TMG no Brasil, no período abordado, corresponderia certa restrição, no plano teórico, que apresenta pequeno 
número de referenciais teóricos e de categorias para abordar a questão, apresentando raras discussões sobre alternativas aos SRT para ampliação de propostas às diferentes necessidades de moradias de pessoas com TMG.

\section{Método}

Levantamos publicaçóes em periódicos indexados nas bases Scopus e Lilacs, escolhidas por constituírem a maior cobertura de resumo, citações e textos completos na literatura científica internacional e nacional (SILVA; GRÁCIO, 2017) e a principal base de dados bibliográficos em Ciências da Saúde na América Latina e Caribe (PACKER; TARDELLI; CASTRO, 2007), respectivamente. Definimos o período entre o ano 2000, de lançamento da portaria GM/MS no 106/00, que criou os SRT, e o ano de 2017. As publicaçôes foram localizadas por meio das palavras "residência", "moradia", "habitação", "casa" e "lar" associadas às palavras "saúde mental", "desinstitucionalização", "esquizofrenia", "transtorno bipolar" e "transtornos mentais".

Os artigos foram levantados de maneira independente por dois pesquisadores distintos. Os dissensos superados por meio de discussão com um terceiro pesquisador. As 58 publicaçóes selecionadas foram lidas na íntegra. A extração de dados dos artigos foi realizada por um pesquisador e revisada por outro, utilizando tabela com: autores, ano de publicação, locais de realização do estudo, temas abordados, estratégias metodológicas, sujeitos de pesquisa, categorias analíticas utilizadas, referenciais bibliográficos e principais conclusóes. Por meio de estudo bibliométrico, analisamos os trabalhos publicados por cada autor e relaçóes de coautoria estabelecidas entre autores com ao menos três estudos sobre o tema. Abordamos as citaçôes, considerando a frequência com que os diferentes autores apareceram nos referenciais teóricos das obras analisadas.

Consideramos como principal limitação deste estudo a possibilidade de que alguns artigos não tenham sido localizados em razão das palavras eleitas para a busca ou por não estarem indexados nas bases utilizadas.

\section{Resultados e Discussão}

\section{Temáticas de análises privilegiadas}

Foram encontradas 58 publicaçôes, variando sua distribuição entre uma e oito por ano (com exceção de 2003, quando nenhum estudo foi publicado), em periódicos 
relacionados à Saúde Coletiva, com 18 publicações nesta área de conhecimento, destacando-se a revista Ciência \& Saúde Coletiva, com oito artigos; relativos à área da Enfermagem, com 16 publicações, com destaque para a revista Texto \& Contexto Enfermagem com quatro artigos; e finalmente, à área de Psicologia, com 13 publicaçôes, com destaque à revista Psicologia \& Sociedade com quatro artigos. Foram encontrados artigos em menor número (entre um e três) em revistas das áreas de Terapia Ocupacional, Psicopatologia, Psiquiatria, Arquitetura e Crescimento e Desenvolvimento Humano (tabela 1).

\section{Tabela 1. Artigos analisados. São Paulo-SP, 2019}

\begin{tabular}{|c|c|c|c|c|}
\hline & Autores & Título Abreviado & Ano & Periódico \\
\hline 1 & Silva et al. & Desinstitucionalização de pacientes de longa... & 2017 & \multirow{8}{*}{ Ciênc Saúde Coletiva } \\
\hline 2 & Fagundes Jr et al. & Reforma psiquiátrica no Rio de Janeiro & 2016 & \\
\hline 3 & Jardim et al. & Limitaçôes de comportamento social entre... & 2015 & \\
\hline 4 & Argiles et al. & Redes de sociabilidade & 2013 & \\
\hline 5 & Furtado et al. & Modos de morar de pessoas com TMG no Brasil & 2013 & \\
\hline 6 & Silveira; Santos Jr & Que eles falem por si & 2011 & \\
\hline 7 & Amorim; Dimenstein & Desinstitucionalização em saúde mental e... & 2009 & \\
\hline 8 & Furtado & Avaliação da situação atual dos SRT no SUS & 2006 & \\
\hline 9 & Lima; Brasil & Do PVC à conquista da autonomia & 2014 & \multirow{3}{*}{ Physis } \\
\hline 10 & Wachs et al. & Processos de subjetivação e territórios de vida & 2010 & \\
\hline 11 & Honorato; Pinheiro & O trabalho do profissional de saúde mental... & 2008 & \\
\hline 12 & Furtado & Subsídios para a diversificação de moradias... & 2013 & \multirow{3}{*}{ Interface } \\
\hline 13 & Furtado et al. & Inserção social e habitação & 2010 & \\
\hline 14 & Romagnoli et al. & Por uma clínica da resistência & 2009 & \\
\hline 15 & Ribeiro Neto; Avellar & Identidade social e desinstitucionalização & 2015 & \multirow{2}{*}{ Saúde Soc } \\
\hline 16 & Suiyama et al. & SRT em saúde mental & 2007 & \\
\hline 17 & Bastos; Aguiar & $\begin{array}{l}\text { Vivências de moradores de RT de Feira de } \\
\text { Santana, Bahia }\end{array}$ & 2011 & $\begin{array}{l}\text { Rev Baiana Saúde } \\
\text { Pública }\end{array}$ \\
\hline 18 & Barros; Josephson & Lares abrigados & 2001 & Saúde Debate \\
\hline
\end{tabular}




\begin{tabular}{|c|c|c|c|c|}
\hline & Autores & Título Abreviado & Ano & Periódico \\
\hline 19 & Almeida Filho et al. & Reab. Psicossoc. em moradias assistidas no... & 2016 & \multirow{4}{*}{$\begin{array}{c}\text { Texto Contexto } \\
\text { Enferm }\end{array}$} \\
\hline 20 & Martins et al. & O processo de implantação de RT em Volta... & 2012 & \\
\hline 21 & Belini; Hirdes & Projeto morada São Pedro & 2006 & \\
\hline 22 & Pereira; Borenstein & Iluminando as vivências de mulheres... & 2004 & \\
\hline 23 & Santos Jr et al. & Residências terapêuticas & 2010 & \multirow{3}{*}{ Online Braz J Nurs } \\
\hline 24 & Macedo; Silveira & A experiência da implantação dos SRT & 2009 & \\
\hline 25 & Santos Jr et al. & Similitudes e diferenças nas temáticas que... & 2008 & \\
\hline 26 & Kantorski et al. & O cotidiano e o viver no SRT & 2014 & \multirow{2}{*}{ Rev Eletrônica Enf } \\
\hline 27 & Kantorski et al. & Metodologia de análise de redes do cotidiano... & 2013 & \\
\hline 28 & Antonacci et al. & Estrutura e fluxo da rede de saúde como... & 2013 & \multirow{2}{*}{ Rev Esc Enferm USP } \\
\hline 29 & Livieres; Aranha e Silva & O projeto moradia assistida do CAPS & 2006 & \\
\hline 30 & Matos; Moreira & SRT: o olhar do usuário & 2013 & \multirow{2}{*}{ Esc Anna Nery } \\
\hline 31 & Silva; Azevedo & A reforma psiquiátrica na visão de quem cuida & 2011 & \\
\hline 32 & Monteiro et al. & O viver e o morar: relaçōes interpessoais... & 2012 & Rev Enferm UERJ \\
\hline 33 & Sprioli; Costa & Cuidar em novo tempo & 2011 & $\begin{array}{l}\text { Rev Latinoam } \\
\text { Enferm }\end{array}$ \\
\hline 34 & Resgalla; Freitas & A residência terapêutica: o melhor lugar de viver & 2004 & $\begin{array}{c}\text { Rev Mineira de } \\
\text { Enferm }\end{array}$ \\
\hline 35 & Ribeiro Neto; Avellar & Concepçóes sobre a interação com moradores... & 2016 & \multirow{3}{*}{ Psicol Soc } \\
\hline 36 & Franco RF, Stralen CJ & Desinstitucionalização psiquiátrica... & 2015 & \\
\hline 37 & Moreira; Andrade & Habitar a cidade: análise de SRT & 2007 & \\
\hline 38 & Bressan; Marcolan & O desvelar de violaçóes dos direitos humanos... & 2016 & \multirow{2}{*}{ Psicol Estud } \\
\hline 39 & Frazatto; Boarini & O morar em hospital psiquiátrico & 2013 & \\
\hline 40 & Leite et al. & Clínica complexa & 2012 & \multirow{2}{*}{ Psico } \\
\hline 41 & Borsa; Eidelwein & Conhecendo a realidade da saúde mental no RS & 2005 & \\
\hline 42 & Venturini & O caminho dos cantos & 2010 & \multirow{2}{*}{ Fractal: Rev de Psicol } \\
\hline 43 & Amorim; Dimenstein & Loucura e cidade & 2009 & \\
\hline 44 & Ribeiro Neto; Avellar & Conhecendo os cuidadores de um SRT & 2009 & \multirow{2}{*}{ Mental } \\
\hline 45 & Fonseca et al. & A moradia protegida no contexto da reforma... & 2008 & \\
\hline
\end{tabular}




\begin{tabular}{|c|c|c|c|c|}
\hline & Autores & Título Abreviado & Ano & Periódico \\
\hline 46 & Generoso & A orientação da psicanálise em um SRT & 2008 & Estud Pesqui Psicol \\
\hline 47 & Marcos & A reinvenção do cotidiano e a clínica possível... & 2004 & Psyche \\
\hline 48 & Sztajnberg; Cavalcanti & Sob o pé do castanheiro & 2014 & \\
\hline 49 & Generoso; Guerra & Desinserção social e habitação & 2012 & Rev Latinoam \\
\hline 50 & Sztajnberg; Cavalcanti & A arte de morar... na Lua & 2010 & Psicopatol Fundam. \\
\hline 51 & Generoso; Guerra & Inserção social e habitação: modos dos... & 2009 & \\
\hline 52 & Mângia; Ricci & Pensando o habitar trajetórias de usuários... & 2011 & \\
\hline 53 & Mângia; Marques & Desinstitucionalização e SRT: novas perspect. & 2004 & Rev Ter Ocup \\
\hline 54 & Mângia; Rosa & Desinstitucionalização e SRT & 2002 & \\
\hline 55 & Vidal et al. & Reforma psiquiátrica e SRT & 2008 & J Bras Psiquiatr \\
\hline 56 & Menezes et al. & Household crowding and compliance with... & 2000 & $\begin{array}{c}\text { Soc Psychiatry } \\
\text { Psychiatr Epidemiol. }\end{array}$ \\
\hline 57 & Baltazar et al. & Spaces for diferences & 2013 & Facilities \\
\hline 58 & Henna et al. & Rede de atenção à saúde mental de base... & 2008 & $\begin{array}{c}\text { Rev Bras } \\
\text { Crescimento Desenv } \\
\text { Hum }\end{array}$ \\
\hline
\end{tabular}

Ressalte-se que, ao realizar o levantamento de artigos, tivemos o cuidado de usar um conjunto de palavras que privilegiou os termos moradia, por um lado, e $T M G$, por outro, de modo a abranger o maior número possível de iniciativas voltadas à clientela considerada, sem especificá-las a priori. Ainda assim, os SRT constituíram o principal objeto das publicaçóes analisadas, representando $86 \%$ do total de artigos, presentes em 14 dos 18 anos considerados, sendo que em oito desses anos de maneira exclusiva (figura 1). Há textos que abordaram os SRT de forma secundária por meio da análise das redes de serviços de saúde mental (HENNA et al., 2008; FAGUNDES JR; DESVIAT; SILVA, 2016) e, indiretamente, a partir de experiências precursoras como os chamados lares abrigados (BARROS; JOSEPHSON, 2001), moradias transitórias (LIVIERES; SILVA, 2006), vilas terapêuticas (BELINI; HIRDES, 2006) e estudo sobre o morar no interior de hospital psiquiátrico (FRAZATTO; BOARINI, 2013). 
Figura 1. Distribuição dos artigos por ano de publicação

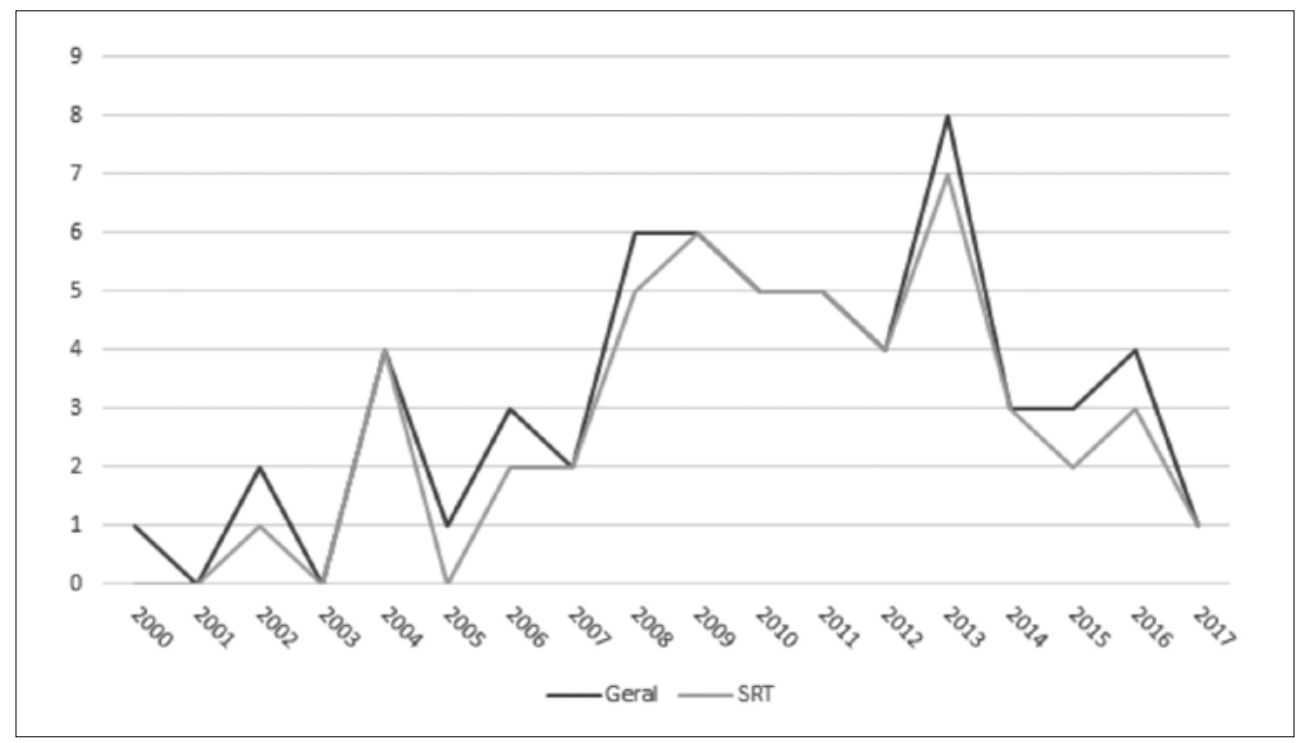

Fonte: elaboração própria.

De maneira geral, o conjunto de estudos aborda os SRT e iniciativas precursoras em perspectiva eminentemente dirigida aos processos de funcionamento dos mesmos, podendo ser analisado segundo sua ênfase: aos fatores envolvidos na transiçáo do hospital para a nova moradia, ao cotidiano no interior das residências, às redes de relaçôes estabelecidas por seus moradores (interna e externamente) e ao trabalho e às atribuiçóes dos profissionais envolvidos na iniciativa.

$\mathrm{Na}$ transiçáo do hospital para as novas moradias, compararam a vida dos moradores antes e depois da saída do hospital (RESGALLA et al., 2004; SZTAJNBERG; CAVALCANTI, 2010; FRANCO; STRALEN, 2015), enfatizando a experiência de autonomia e satisfaçáo, mesmo quando exercidas nos limites da residência, com pouca interação e inserção comunitária, desconsiderando desafios e limitaçóes advindos das soluçóes materializadas nos SRT. O cotidiano dos moradores foi analisado, por parte dos autores, de forma abrangente (KANTORSKI et al., 2014; LIMA; BRASIL, 2014), considerandose perspectivas como a relação com o território, os conflitos entre os pares e as dificuldades provenientes dos anos de institucionalização. No entanto, alguns estudos apresentaram este conceito de maneira simplificada, próximo da noção 
de atividades de vida diária, oriunda da reabilitação física, sem problematizar os efeitos dessa rotina sobre os anseios de cada um dos moradores.

As redes de relaçóes dos moradores foram abordadas por meio das interaçóes estabelecidas entre si e com os profissionais responsáveis pelos SRT (ARGILES et al., 2013; FURTADO et al., 2013a; MATOS; MOREIRA, 2013; RIBEIRO NETO; AVELLAR, 2015). Fora do ambiente domiciliar, as análises incluíram os vizinhos (AMORIM; DIMENSTEIN, 2009a; BASTOS; AGUIAR, 2011; MONTEIRO et al., 2012) e as famílias de origem (FONSECA et al., 2008; SILVEIRA; SANTOS JR., 2011; KANTORSKI et al., 2013; LIMA; BRASIL, 2014; SZTAJNBERG; CAVALCANTI, 2014; FRANCO; STRALEN, 2015), retratando eventuais conflitos e dificuldades relacionais. Atores como outros usuários do CAPS, amigos ou parceiros amorosos não foram considerados nos estudos. As análises sobre o processo de trabalho se restringiram aos profissionais diretamente ligados aos SRT, problematizando os limites e possibilidades para a atuação em um novo contexto laboral (ROMAGNOLI et al., 2009; SILVEIRA; SANTOS JR., 2011; SPRIOLI; COSTA, 2011; LEITE et al., 2012; FURTADO et al., 2013a). A ausência de atores como profissionais dos CAPS, de outros serviços de saúde ou até mesmo de outras áreas, como a educação, assistência social ou habitação, parece refletir as dificuldades enfrentadas na relação com outros serviços e setores, desconsiderando pontos de vista que poderiam ampliar a compreensão e proposiçôes ao enfrentamento da questão.

Dentre os temas citados acima, faltam abordagens que coloquem a própria intervenção em perspectiva, indagando e buscando levantar questóes relativas às limitaçóes intrínsecas à proposta. Afinal, quais seriam as limitaçôes de um pretenso lar baseado em característica comum de seus integrantes, no caso uma carreira psiquiátrica? Qual a permeabilidade da proposta aos habitus pregressos de moradia de seus moradores? Que anseios, imaginários e perspectivas de moradia permeiam a clientela alvo dos SRT? Que novas perspectivas se impóem, no horizonte do morar para essa clientela, após o primeiro passo representado pela portaria GM/MS no 106/2000? Naturalmente, olhar para dentro, descrevendo e analisando os processos envolvidos nos SRT contribui para qualificá-los. Autores como Baltazar et al. (2013) e Furtado e Nakamura (2014), por exemplo, identificaram algumas limitaçôes relacionadas à possibilidade dos moradores poderem de fato habitar seus novos lares. $\mathrm{O}$ conjunto de categorias aqui sistematizado indica a necessidade de enriquecer temas de análise, de modo a aprofundar o debate. 


\section{Autores e grupos de estudos - principais enfoques}

Os 123 autores, identificados no conjunto de artigos considerados, estáo inseridos, majoritariamente, em instituições públicas de ensino superior, as quais abrigam 84 autores, seguido pelos serviços de saúde com 17 autores, sendo que os demais autores são vinculados a instituiçôes privadas de ensino, instituições estrangeiras ou não declararam o vínculo institucional.

O conjunto de autores concentra-se nas regióes Sul e Sudeste do país, com 31 autores do Rio Grande do Sul, 24 de São Paulo, 21 do Rio de Janeiro e 18 de Minas Gerais. Quinze autores são da Regiáo Nordeste e nenhum das regiôes Norte e Centro-Oeste. Tendo em vista a distribuição dos SRT (DATASUS, 2019), com 272 unidades na Região Sudeste, 78 na Região Nordeste, 26 na Região Sul, 13 no Centro-Oeste e 5 no Norte, observa-se que a quantidade de autores parece refletir a quantidade de serviços existentes. A Região Sul é uma exceção, com grande quantidade de autores e relativamente pequeno número de residências.

Catorze autores podem ser considerados como os mais prolíficos desta área, conforme estabelecido por Price (1986) em sua Lei do Elitismo, e são responsáveis por 30 dos 58 artigos, com participação em ao menos três publicaçōes (tabela 2). A análise das relações de coautoria estabelecida por esses autores revela a formação de sete agrupamentos, em que há associações temáticas e teóricas entre os integrantes.

\section{Tabela 2. Autores com pelo menos três publicaçôes. São Paulo-SP, 2019}

\begin{tabular}{lc}
\hline Autores & Publicaçóes \\
\hline Generoso, C.M. & 6 \\
Furtado, J.P. & 5 \\
Kantorski, L.P. & 5 \\
Guerra, A.M.C. & 4 \\
Silveira, M.F.A. & 4 \\
Amorim, A.K.D.M.A. & 3 \\
Avellar, L.Z. & 3 \\
Cavalcanti, M.T. & 3 \\
Coimbra, V.C.C. & 3
\end{tabular}

continua... 


\begin{tabular}{lc}
\hline Autores & Publicaçóes \\
\hline Tugny, .A & 3 \\
Dimenstein, M. & 3 \\
Mângia, E.F. & 3 \\
Ribeiro Neto, P.M. & 3 \\
Santos Junior, H.P.O. & 3 \\
\hline
\end{tabular}

Fonte: elaboração própria.

Esses agrupamentos resultaram, em parte, das relaçóes entre orientadores e orientandos, parceria usual no meio acadêmico científico (GRÁCIO, 2018) e característico do processo de formação de pesquisadores no Brasil (HILÁRIO; CASTANHA; GRÁCIO, 2017). Outra parte esteve relacionada à colaboração de pesquisadores em torno de um mesmo projeto de pesquisa, a partir de editais de financiamento público, como um estudo realizado na região sul do país, que resultou em cinco dos artigos analisados (ANTONACCI et al., 2013; ARGILES et al., 2013; KANTORSKI et al., 2013, 2014; JARDIM et al., 2015), e outro, realizado em três cidades das regiōes sudeste e centro-oeste, com a publicação de outros cinco artigos (GUERRA; GENEROSO, 2009; FURTADO et al., 2010, 2013a; GENEROSO; GUERRA, 2012; BALTAZAR et al., 2013). Uma terceira forma de colaboração se deu a partir da relação entre membros da academia e atores ligados à gestão (MANGIA; RICCI, 2011; SILVA et al., 2017), porém de forma tímida quando comparada aos demais modos de colaboração.

Apesar do grande interesse dos estudos sobre os trabalhadores e processos de trabalho envolvidos, a participação desses atores nas diferentes fases da pesquisa, incluindo a escrita de publicaçóes científicas, é restrita. Desta forma, quem produz o conhecimento e quem conduz a prática ocupam lugares hierarquicamente distintos na pesquisa, semelhante ao observado em relação a quem produz e quem executa as políticas públicas (LOTTA, 2014). Nesse caso específico, mais interação entre aqueles que conduzem as práticas e aqueles que se dispóem a abordá-las, articulando-se em torno de esforços de sistematização da experiência, talvez pudesse contribuir para o avanço tanto da análise quanto da proposição de alternativas de ampliação qualitativa e dos gradientes de suportes a serem oferecidos à moradia de pessoas com TMG. 
Chama a atenção certo fechamento dos grupos que compóem as redes de colaboração e coautoria. Tais grupos encerram-se em regiốes do país, metodologia e outros modos de abordar o problema com nenhuma interação com os demais, indicando pouca troca e interação em torno de uma questão que lhes é comum.

\section{Sujeitos e estratégias metodológicas utilizadas na abordagem do tema}

Tomando como base o que se configurou como sujeito de pesquisa e respectivas fontes de informaçôes dos artigos analisados, percebe-se mais interesse sobre os próprios moradores, que constituem objeto exclusivo em 21 dos estudos realizados. Outros 14 artigos constituíram os trabalhadores das SRT como foco de interesse e seis envolveram tanto moradores quanto trabalhadores. Os vizinhos dos SRT foram considerados em dois estudos, enquanto os familiares apenas em um, voltado a conhecer a trajetória de egressos de um hospital psiquiátrico a partir da narrativa de seus familiares.

Ademais, a própria escolha dos moradores e trabalhadores como principais sujeitos de interesse dos estudos denota um posicionamento ético-político coerente com o pensamento predominante na reforma psiquiátrica brasileira que propóe a transformação do lugar do louco como ator social (TORRE; AMARANTE, 2001), em contraponto a perspectivas que o consideram apenas a partir de sua doença (KINOSHITA, 2010), e do lugar do trabalhador como sujeito tomado de responsabilidade por esta transformação (ROTELLI; DE LEONARDIS; MAURI, 2001).

Os estudos empregados incluem o espectro que vai dos desenhos quantitativos aos qualitativos, incluindo abordagens mistas e estudos não empíricos e com a utilização de dados secundários. As metodologias qualitativas são predominantes e estão presentes em 42 dos artigos analisados, sendo seguidas numericamente pelos 11 artigos produzidos a partir de desenhos não empíricos e com a utilização de dados secundários, como revisôes bibliográficas, estudos documentais, ensaios e discussões metodológicas. Dentre os estudos qualitativos, foram encontrados 27 estudos de caso, dois relatos de experiência, seis estudos de casos clínicos, cinco estudos com abordagem etnográfica, uma pesquisa-ação e uma pesquisa-intervenção. Por outro lado, dentre as pesquisas classificadas como quantitativas, foram encontrados apenas um estudo com desenho experimental, um desenho observacional transversal, um observacional longitudinal e um desenho misto (tabela 3). 
Considerando-se que as escolhas metodológicas ultrapassam a simples definição de meios mais apropriados para se abordar um determinado objeto, refletindo as tomadas de posiçóes dos autores envolvidos diante do debate que permeia as diferentes concepções e entendimentos sobre a realidade (FURTADO, 2018), pode-se considerar que o elevado número de desenhos qualitativos reflete um posicionamento próprio da área da Saúde Mental ao lidar com o fenômeno a partir de sua complexidade (ROTELLI; DE LEONARDIS; MAURI, 2001), ressaltando os efeitos subjetivos e as concepçóes dos atores envolvidos (CAMPOS; ONOCKOCAMPOS; DEL BARRIO, 2013).

Tabela 3. Distribuiçấo dos artigos por tipos de estudo, sujeitos e fontes de informação e categorias analíticas. São Paulo-SP, 2019

\begin{tabular}{|c|c|c|}
\hline Método & Tipo de estudo & Artigos* \\
\hline \multirow{3}{*}{ Quantitativo } & Estudo experimental & 1 \\
\hline & Coorte & 56 \\
\hline & Estudo Transversal & 3 \\
\hline \multirow{6}{*}{ Qualitativo } & Caso Clínico & $29,46,47,48,49,50$ \\
\hline & Estudo de caso & $\begin{array}{l}4,5,6,7,9,11,14,18,19,20,21,22,23,25, \\
26,27,28,30,31,32,34,38,39,41,43,44,57\end{array}$ \\
\hline & Etnografia & $15,17,33,35,52$ \\
\hline & Pesquisa-ação & 36 \\
\hline & Pesquisa-intervenção & 10 \\
\hline & Relato de experiência & 40,45 \\
\hline Misto & $\begin{array}{l}\text { Estudo transversal e estudo } \\
\text { de caso }\end{array}$ & 24 \\
\hline \multirow{4}{*}{$\begin{array}{l}\text { Estudos não } \\
\text { empíricos ou com } \\
\text { dados secundários }\end{array}$} & Pesquisa bibliográfica & $12,16,55$ \\
\hline & Discussão metodológica & 13 \\
\hline & Ensaio & $37,42,51,53,54$ \\
\hline & Análise documental & $2,8,58$ \\
\hline
\end{tabular}

continua... 


\begin{tabular}{|c|c|}
\hline Tipo de estudo & Artigos * \\
\hline \multicolumn{2}{|l|}{ Sujeitos e fontes de informação } \\
\hline Moradores & $\begin{array}{l}1,3,9,17,22,24,26,27,29,30,32,34,36,46 \\
47,48,49,50,52,56,57\end{array}$ \\
\hline Trabalhadores & $4,6,11,14,18,19,20,21,28,31,33,38,43,44$ \\
\hline Moradores e Trabalhadores & $5,7,10,23,25,41$ \\
\hline Vizinhos & 15,35 \\
\hline Familiares & 39 \\
\hline Artigos científicos e documentos diversos & $2,8,12,16,55,58$ \\
\hline \multicolumn{2}{|l|}{ Categorias de Análise } \\
\hline Convívio Social & $3,4,11,15,17,22,27,32,35,50,52$ \\
\hline Suporte & $\begin{array}{l}1,5,7,9,10,19,13,14,18,21,24,26,28,29 \\
36,37,39,41,42,43,45,46,47,48,49,55,56 \\
57,58\end{array}$ \\
\hline Conformidade com as normas & $2,19,30,38$ \\
\hline Satisfação & 34 \\
\hline Prática profissional & $6,18,20,23,25,31,33,40,44,45,50,51$ \\
\hline Contexto & $8,12,16,53,54$ \\
\hline
\end{tabular}

* Números referentes aos artigos presentes na Tabela 1

Fonte: elaboração própria.

De forma geral, os estudos nacionais sobre moradia são, majoritariamente, qualitativos, ligados aos processos de trabalho e ao cotidiano das residências e têm os trabalhadores e usuários como principais sujeitos de pesquisa, e, como consequência, abordam aspectos relacionados ao convívio social, suporte e práticas profissionais.

\section{Referenciais bibliográficos utilizados}

Identificaram-se 1011 autores referenciados nos artigos analisados e, destes, 37 estiveram presentes em pelo menos $10 \%$ das publicaçóes, podendo ser considerados como de maior impacto e visibilidade (GRÁCIO; OLIVEIRA, 2013). Destaca-se, entre os mais citados, o Ministério da Saúde do Brasil, com 124 citaçóes, presente em 45 dos artigos analisados (tabela 4), seguido pelo autor brasileiro, pioneiro da reforma 
psiquiátrica nacional, Paulo Amarante, com 38 citações em 27 artigos diferentes. Três autores italianos, Benedetto Saraceno, Franco Rotelli e Franco Basaglia, que participaram ativamente da experiência triestina e influenciaram significativamente a reestruturação da atenção em saúde mental no Brasil também figuram entre os mais citados, com 27, 18 e 14 citaçóes, respectivamente.

Tabela 4. Autores, número de citações e número de artigos em que foram citados. São Paulo-SP, 2019

\begin{tabular}{|c|c|c|c|c|c|}
\hline Autor citado & Citaçôes & $\begin{array}{l}\mathrm{N}^{\circ} \text { de artigos em } \\
\text { que foram citados }\end{array}$ & Autor citado & Citaçôes & $\begin{array}{l}\mathrm{N}^{\circ} \text { de artigos em } \\
\text { que foram citados }\end{array}$ \\
\hline Min. da Saúde & 124 & 45 & Delgado, P.G.G. & 9 & 7 \\
\hline Amarante, P. & 38 & 27 & Barros, R.B. & 9 & 7 \\
\hline Furtado, J.P. & 30 & 21 & Gonçalves, S. & 9 & 6 \\
\hline Saraceno, B. & 27 & 24 & Dimenstein, M. & 8 & 8 \\
\hline Rotelli, F & 18 & 15 & Guimarães, J. & 8 & 8 \\
\hline Goffmam, E. & 17 & 16 & Pacheco, R.A. & 8 & 8 \\
\hline OMS & 14 & 10 & Campos, R.O. & 8 & 7 \\
\hline Basaglia, F. & 14 & 10 & Saeki, T. & 8 & 7 \\
\hline Foucault, M. & 14 & 8 & Vasconcelos, E.M. & 8 & 7 \\
\hline Minayo, M.C.S. & 12 & 12 & Lovisi, G. & 8 & 6 \\
\hline Lima, L.A. & 12 & 7 & Gontijo, E. & 7 & 7 \\
\hline Guattari, F. & 11 & 8 & Paulon, S.M. & 7 & 7 \\
\hline De Leonardis, O. & 10 & 10 & Fagundes, P. & 7 & 6 \\
\hline Mauri, D. & 10 & 10 & Lesage, A. & 7 & 6 \\
\hline Campos, F.C.B. & 10 & 7 & Kinoshita, R.T. & 7 & 6 \\
\hline Barros, S. & 10 & 7 & Bardin, L. & 6 & 6 \\
\hline Leff, J. & 10 & 6 & Resende, V. & 6 & 6 \\
\hline Bandeira, M. & 9 & 8 & Desviat, M. & 6 & 6 \\
\hline Vidal, C. & 9 & 8 & & & \\
\hline
\end{tabular}

Fonte: elaboração própria. 
Autores brasileiros que dedicaram parte da sua produção ao tema da moradia para pessoas com TMG também estão presentes nas referências dos estudos analisados, com destaque para Juarez Furtado, referido em 21 dos artigos analisados, com 30 citaçóes no total. Autores norte-americanos e canadenses que tratam deste tema, como Leff e Lesage, aparecem em menor número, com dez e sete citaçôes, respectivamente.

Os artigos analisados trazem também, em significativa quantidade, citações a autores com obras na área da sociologia, como Erving Goffman, citado 17 vezes em 16 publicaçôes diferentes, e da filosofia, como Michel Foucault e Félix Guattari, ambos presentes em oito publicaçôes. Por fim, é possível identificar o alto número de citaçóes a autoras com obras relacionadas à metodologia qualitativa, como Cecília Minayo e Laurence Bardin, citadas em 12 e 6 artigos, respectivamente, o que parece se alinhar ao maior número de estratégias qualitativas, conforme já discutido.

De forma semelhante ao ocorrido no próprio processo de reforma psiquiátrica brasileiro em que o Ministério da Saúde induziu e orientou de modo direto a implantaçáo da rede de atençáo psicossocial (COSTA-ROSA, 2013), no campo científico, este agente também assume importância nas discussóes sobre o tema das moradias, como atestam as citaçóes recorrentes às normativas e cartilhas de orientaçóes. Praticamente na totalidade dos estudos, as publicações do MS figuram como baliza e parâmetro, raramente constituindo objeto de debate, questionamento e discussão sobre as suas limitaçóes e eventuais avanços a serem alcançados na intervenção proposta no interior do SUS para o tema aqui abordado.

A análise dos referenciais bibliográficos evidencia a centralidade que determinados autores seminais da Reforma Psiquiátrica Brasileira assumem, no campo científico, para as abordagens da questão. Autores como Franco Basaglia, Michel Foucault e Félix Guattari, que vieram pessoalmente ao país, entre os anos 1975 e 1980, e instigaram centenas de "jovens inquietos" (PITTA, 2011), permanecem como interlocutores privilegiados no diálogo com a produção sobre o tema. Se por um lado, a presença destes autores reafirma as importantes contribuições epistemológicas que trouxeram para a constituição do pensamento atual, também evidencia certa paralisação do pensamento na área, uma vez que a entrada de mais interlocutores poderia ensejar novos diálogos e ampliar as reflexóes e soluçôes atualmente adotadas na política de saúde mental, particularmente, em relação à moradia para pessoas com TMG. 


\section{Considerações finais}

O surgimento, no final dos anos 90, da demanda por políticas públicas que atendessem à necessidade de moradia dos egressos de hospitais psiquiátricos e a decorrente criaçấo dos SRT, no ano 2000, gerou expectativa de um significativo aumento das investigaçóes sobre a temática da moradia para pessoas com TMG (MANGIA; ROSA, 2002). Entretanto, estas permaneceram escassas, como pudemos constatar, e dedicadas, quase que exclusivamente, à análise dos serviços residenciais terapêuticos, única alternativa de moradia oferecida pelo Estado para pessoas com TMG.

Nesse contexto, a contribuição acadêmica tem sido tímida na oferta de aportes que subsidiem a construção de novas alternativas no contexto do reordenamento da atenção em saúde mental no país, o que parece convergir com o pressuposto da presente investigaçáo, de que ao restrito leque de opçóes e alternativas ao morar corresponderiam modos igualmente restritos de tematizar e analisar a questão na literatura científica. De certa forma, a literatura analisada se mostrou aquém do que o avanço do suporte à moradia exige para a sua efetiva expansão, tanto numérica quanto qualitativa, essa última materializada nas diferentes formas de suportes necessários à variedade de indivíduos envolvidos e respectivos anseios no estabelecimento de suas formas de morar.

Os estudos analisados, em alguns aspectos, mostraram-se limitados em relação aos temas abordados, prevalecendo aqueles relacionados aos processos de funcionamento dos SRT. Os textos considerados privilegiam a descrição do funcionamento das moradias e abordam, predominantemente, os processos de trabalho e suporte, com categorias analíticas restritas e referenciais teóricos pouco variados, oriundos, em sua maioria, de textos seminais que embasaram o início da reforma psiquiátrica brasileira. Esse conjunto de características parece explicar a circunscrição do debate ao único equipamento existente oficialmente - os SRT - e, ao mesmo tempo, evidencia a baixa porosidade às iniciativas desenvolvidas em outros países e à formulação de novos modelos, mais adaptados às questôes contemporâneas que permeiam o morar e o habitar da clientela aqui enfocada, considerando as mais de duas décadas da publicação da portaria 106/2000.

$\mathrm{O}$ desenvolvimento de estudos que permitam conhecer de maneira ampliada o modo como as diversas pessoas com TMG constituem sua moradia e, a partir 
dela, inserem-se socialmente, com uso de diferentes estratégias metodológicas, poderia contribuir para uma melhor compreensão das necessidades enfrentadas por este público e trazer novos subsídios para enfrentamentos e proposiçôes quanto às políticas públicas no campo da saúde mental (FURTADO et al., 2013b). Ao mesmo tempo, novos referenciais teóricos deveriam ser agregados àqueles que têm se mostrado efetivos para abordar o tema, acrescidos de experiências inovadoras e menos restritivas, como aquelas representadas pelo Housing First (GILMER et al., 2014), modelo de origem estadunidense, voltado a pessoas que não possuem habitaçóes estáveis e que fornece, prontamente, acesso à moradia e à equipe de suporte, respeitando as escolhas dos usuários.

Desse modo, pretende-se reafirmar que o avanço e ampliação quantitativa e qualitativa da produçáo acadêmica sobre o apoio à moradia de pessoas com TMG mostra-se urgente. Afinal há novos desafios decorrentes da própria reforma da atenção em saúde mental que apresenta a necessidade de avanço na desinstitucionalização de todas as pessoas que ainda se encontram na condição de moradores em hospitais psiquiátricos e na atenção a outros milhares de indivíduos acompanhados pelas RAPS e sem acesso a alternativas de moradia que atendam às suas necessidades, cada vez mais complexas.

O que vimos afirmando poderia auxiliar na qualificação ao enfrentamento das questóes de moradias de pessoas com TMG e, por outro lado, promover o debate em torno de recentes portarias do Ministério da Saúde, que passaram a incluir os hospitais psiquiátricos nas RAPS (BRASIL, 2017; BRASIL, 2019), aumentaram o valor das diárias dos leitos de longa permanência (BRASIL, 2018) e podem colocar em risco as insuficientes unidades residenciais existentes, ao aumentar o número de moradores sem modificar as condições dos SRT (BRASIL, 2017; BRASIL 2019). Nesse último caso, corre-se o risco de reinventar situaçóes que se buscou superar, como o acúmulo de pessoas agrupadas em imóveis congregados, porém separados da comunidade mais geral, tendo em comum apenas o fato de ser alvo de estigma social. ${ }^{1}$

\section{Referências}

ALMEIDA FILHO, A. J.; QUEIRÓS, P. J. P.; RODRIGUES, M. A. Reabilitação psicossocial em moradias assistidas no Brasil e em Portugal. Texto Contexto Enferm. Florianópolis, v. 25, n. 1, p. 1-9, 2016. 
AMORIM, A. K. A.; DIMENSTEIN, M. Loucura e cidade: cenas biopolíticas e incursōes (des) institucionalizantes. Fractal: Revista de Psicologia. Niterói, v. 21, n. 2, p. 319-335, ago. 2009a.

. Desinstitucionalização em saúde mental e práticas de cuidado no contexto do serviço residencial terapêutico. Ciênc. Saúde Colet. Rio de Janeiro, v. 14, n. 1, p. 195-204, fev. 2009 b.

ANTONACCI, M. H. et al. Estrutura e fluxo da rede de saúde como possibilidade de mudança nos serviços de atenção psicossocial. Rev. Esc. Enferm. USP. São Paulo, v. 47, n. 4, p. 891-8, ago. 2013.

ARGILES, C. T. L. et al. Redes de sociabilidade: construções a partir do serviço residencial terapêutico. Ciênc. Saúde Colet. Rio de Janeiro, v. 18, n. 7, p. 2049-2058, jul. 2013.

BALTAZAR, A. P. et al. Spaces for differences: dwelling after deinstitutionalization. Facilities, v. 31, n. 9/10, p. 407-417, 2013.

BARBATO, A.; CIVENTI, G.; D’AVANZO, B. Community residential facilities in mental health services: A ten-year comparison in Lombardia. Health Policy, v. 121, n. 6, p. 623628, 2017.

BARROS, R. B.; JOSEPHSON, S. Lares abrigados: dispositivo clínico-político no impasse da relaçäo com a cidade. Saúde Debate. Londrina, v. 25, n. 58, p. 57-69, 2001.

BASTOS, L. C.; AGUIAR, M. G. G. Vivências de moradores de residências terapêuticas de Feira de Santana, Bahia: do Fio da vida administrada no "hospital Colônia" à vida em liberdade na cidade. Rev. Baiana de Saúde Pública. Salvador, p. 432-445, 2011.

BELINI, M. G.; HIRDES, A. Projeto morada São Pedro: da institucionalização à desinstitucionalização em saúde mental. Texto Contexto Enferm. Florianópolis, v. 15, n. 4, p. 562-569, 2006.

BORSA, J. C.; EIDELWEIN, K. Conhecendo a realidade da saúde mental no Rio Grande do Sul. Psico. Porto Alegre, v. 36, n. 2, p. 159-165, 2005.

BRASIL, Ministério da Saúde. Legislação em Saúde Mental: 1990-2004. 5a ampl. ed. Brasília: Ministério da Saúde, 2004.

Portaria no 3.090, de 23 de dezembro de 2011. Altera a Portaria no 106/GM/MS, de 11 de fevereiro de 2000, e dispóe, no âmbito da Rede de Atenção Psicossocial, sobre o repasse de recursos de incentivo de custeio e custeio mensal para implantação e/ou implementação e funcionamento dos Serviços Residenciais Terapêuticos (SRT). Diário Oficial da União, Brasília, DF, 30 dez. 2011, Seção 1, p. 62-63.

. Portaria no 3.588, de 21 de dezembro de 2017. Altera as Portarias de Consolidação no 3 e no 6, de 28 de setembro de 2017, para dispor sobre a Rede de Atençáo Psicossocial, e dá outras providências. Diário Oficial da União, Brasília, DF, 22 dez. 2017, Seção 1, p. 236-238. 
. Portaria n 2.434 , de 15 de agosto de 2018. Altera a Portaria de Consolidação n ${ }^{\circ}$ 6/ GM/MS, de 28 de setembro de 2017, para reajustar o valor das diárias de internação hospitalar acima de 90 (noventa) dias do Incentivo para Internação nos Hospitais Psiquiátricos. Diário Oficial da União, Brasília, DF, 20 ago. 2018, Seção 1, p. 38-39.

. Nota Técnica $n^{\circ}$ 11: Esclarecimentos sobre as mudanças na Política Nacional de Saúde Mental e nas Diretrizes da Política Nacional sobre Drogas. Brasília: Ministério da Saúde, 2019. BRESSAN, V. R.; MARCOLAN, J. F. O desvelar de violaçóes dos direitos humanos em serviços residenciais terapêuticos. Psicol. Estud. Maringá, v. 21, n. 1, p. 149-160, 2016.

CAMPOS, G. W. S.; ONOCKO-CAMPOS, R. T.; DEL BARRIO, L. R. Políticas e práticas em saúde mental: as evidências em questão. Ciênc. Saúde Colet. Rio de Janeiro, v. 18, n. 10, p. 2797-2805, 2013.

COSTA-ROSA, A. Atenção Psicossocial para além da Reforma Psiquiátrica: Contribuições a uma Clínica Crítica dos processos de Subjetivação na Saúde Coletiva. São Paulo: EdUNESP, 2013.

DEPARTAMENTO DE INFORMÁTICA DO SUS (DATASUS). Cadastro Nacional de Estabelecimentos de Saúde. Disponível em: <http://cnes.datasus.gov.br/>. Acesso em: 18 out. 2019.

FAGUNDES JR, H. M.; DESVIAT, M.; SILVA, P. R. F. Reforma Psiquiátrica no Rio de Janeiro: situação atual e perspectivas futuras. Ciênc. Saúde Colet. Rio de Janeiro, v. 21, n. 5, p. 1449-1460, 2016.

FONSECA, P. C. et al. A moradia protegida no contexto da reforma psiquiátrica: interlocuçóes com a família e o campo social. Mental. Barbacena, v. 6, n. 10, p. 69-83, 2008.

FRANCO, R. F.; STRALEN, C. J. VAN. Desinstitucionalização psiquiátrica: do confinamento ao habitar na cidade de Belo Horizonte. Psicol. Soc. Porto Alegre, v. 27, n. 2, p. 312-321, ago. 2015.

FRAZATTO, C. F.; BOARINI, M. L. O “morar” em hospital psiquiátrico: histórias contadas por familiares de "ex-moradores". Psicol. Estud. Maringá, v. 18, n. 2, p. 257-267, 2013.

FURTADO, J. P. Avaliação da situação atual dos Serviços Residenciais Terapêuticos no SUS. Ciênc. Saúde Colet. Rio de Janeiro, v. 11, n. 3, p. 785-795, 2006.

- Subsídios para a diversificação de moradias destinadas a pessoas com transtorno mental grave no Brasil: uma revisão. Interface. Botucatu, v. 17, n. 26, p. 635-647, 2013.

. Construçóes imperfeitas: hospitalidade aos doentes mentais no Brasil. In: FURTADO, J. P.; NAKAMURA, E. (Org.). Inserção Social e Habitação de Pessoas com sofrimento mental grave. São Paulo: FAP-UNIFESP, 2014. p. 43-64.

. Por que avalio? Como avalio? O que aprendi ao avaliar? 2018. Tese (Livre Docência em Planejamento e Gestão em Saúde). Universidade Federal de São Paulo, São Paulo, 2018. 
FURTADO, J. P. et al. Inserção social e habitação: um caminho para a avaliação da situação de moradia de portadores de transtorno mental grave no Brasil. Interface, Botucatu, v. 14, n. 33, p. 289-400, 2010.

- Modos de morar de pessoas com transtorno mental grave no Brasil: uma avaliação interdisciplinar. Ciênc. Saúde Colet. Rio de Janeiro, v. 18, n. 12, p. 3683-93, 2013 a.

- Desenvolvimento de Questionário dirigido às condições de moradia de usuários de CAPS. Saúde Debate. Londrina, v. 37, n. 96, p. 62-75, 2013 b.

FURTADO, J. P.; NAKAMURA, E. (Orgs.). Inserção Social e Habitação de Pessoas com sofrimento mental grave. São Paulo: FAP-UNIFESP, 2014.

FURTADO, J. P.; PACHECO, R. A. Moradias extra-hospitalares para pacientes psiquiátricos em Campinas: análise de uma experiência. J. Bras. Psiquiatr. Rio de Janeiro, v. 47, n. 4, p. 179184, 1998.

GENEROSO, C. M. A orientação da psicanálise em um serviço residencial terapêutico: a casa de aposentados - uma pequena construção. Estud. Pesqui. Psicol. Rio de Janeiro, v. 8, n. 1, p. 67-73, 2008.

GENEROSO, C. M.; GUERRA, A. M. C. Desinserção social e habitação: a psicanálise na reforma psiquiátrica brasileira. Rev. Latinoam. Psicopatol. Fundam. São Paulo, v. 15, n. 3, p. 524-539, 2012.

GILMER, T. P. et al. Fidelity to the housing first model and effectiveness of permanent supported housing programs in California. Psychiatr. Serv., v. 60, n.11, p. 467-474, 2015.

GRÁCIO, M. C. C. Colaboração científica: indicadores relacionais de coautoria. Braz. J. Inf. Sci. Marília, v. 12, n. 2, p. 24-32, 2018.

GRÁCIO, M. C. C.; OLIVEIRA, E. F. T. Análise de cocitação de autores: um estudo teóricometodológico dos indicadores de proximidade, aplicados ao GT7 da ANCIB. Liinc em Revista. Rio de Janeiro, v. 9, n. 1, p. 196-213, 2013.

GUERRA, A. M. C.; GENEROSO, C. M. Inserção social e habitação: modos dos portadores de transtornos mentais habitarem a vida na perspectiva psicanalítica. Rev. Latinoam. Psicopatol. Fundam. São Paulo, v. 12, n. 4, p. 714-730, 2009.

GUILHERMANO NETO, J.; OLIVEIRA, M. O acompanhamento terapêutico e a equipe itinerante. Porto Alegre: Arquivos da Pensão Nova Vida, 2003.

GUIMARÁES, J.; SAEKI, T. Janelas do Santa Tereza: estudo do processo de reabilitação psicossocial do hospital psiquiátrico de Ribeirão Preto (SP). Hist. Ciênc. Saúde-Manguinhos. Rio de Janeiro, v. 8, n. 2, p. 357-374, 2001.

HENNA, E. S. et al. Rede de atenção à saúde mental de base comunitária: a experiência de Santo André. Rev. Bras. Crescimento Desenvolv. Hum. São Paulo, v. 18, n. 1, p. 16-26, 2008. 
HILÁRIO, C.; CASTANHA, R. G.; GRÁCIO, M. C. C. A influência da genealogia acadêmica na colaboração científica: um estudo no campo da Matemática no Brasil. Rev. Guillermo de Ockham. Cali, v. 15, n. 2, p. 133-141, 2017.

HONORATO, C. E. DE M.; PINHEIRO, R. O trabalho do profissional de saúde mental em um processo de desinstitucionalização. Physis. Rio de Janeiro, v. 18, n. 2, p. 361-380, 2008.

JARDIM, V. M. R. et al. Limitaçóes de comportamento social entre usuários da Rede de Atenção Psicossocial no sul do Brasil. Ciênc Saúde Colet. Rio de Janeiro, v. 20, n. 5, p. 1371$1378,2015$.

KANTORSKI, L. P. et al. Metodologia de Análise de Redes do Cotidiano num Serviço Residencial Terapêutico: um estudo de caso. Rev. Eletr. Enferm. Goiânia, v. 15, n. 1, p. 61-70, 2013.

KANTORSKI, L. P. et al. O cotidiano e o viver no Serviço Residencial Terapêutico. Rev. Eletr. Enferm. Goiânia, v. 16, n. 4, p. 759-768, 2014.

KINOSHITA, R. T. Contratualidade e Reabilitação Psicossocial. In: PITTA, A. (Org.). Reabilitação Psicossocial no Brasil. São Paulo: Hucitec, 2010. p. 55-9.

LEFF, H. S. et al. Does one size fit all? What we can and can't learn from a meta-analysis of housing models for persons with mental illness. Psychiatr Serv., v. 60, n. 4, p. 473-482, 2009.

LEITE, L. S. et al. Clínica Complexa: A Experiência Clínica em um Residencial Terapêutico de Caráter Temporário. Psico. Porto Alegre, v. 43, n. 4, p. 517-523, 2012.

LIMA, S. S.; BRASIL, S. A. Do Programa de Volta para Casa à conquista da autonomia: percursos necessários para o real processo de desinstitucionalizaçáo. Physis. Rio de Janeiro, v. 24, n. 1, p. 67-88, 2014.

LIVIERES, C. F.; SILVA, A. L. A. O projeto moradia assistida do centro de atenção psicossocial: de uma questão clínica a outra. Rev. Esc. Enferm. USP. São Paulo, v. 40, n. 2, p. 188-195, 2006. LOTTA, G. S. Agentes de implementação: uma forma de análise de políticas públicas. Cad. Gest. Pública Cidad. São Paulo, v. 19, n. 65, p. 186-206, 2014.

MACEDO, J. Q.; SILVEIRA, M. DE F. DE A. A experiência da implantação dos Serviços Residenciais Terapêuticos - Análise quantitativa e qualitativa. Online Braz. J. Nurs. Rio de Janeiro, v. 8, n. 2, 2009. Disponível em: <http://www.objnursing.uff.br/index.php/nursing/ article/view/j.1676-4285.2009.2375> Acesso em: 8 ago. 2018.

MÂNGIA, E. F.; MARQUES, A. L. M. Desinstitucionalização e serviços residenciais terapêuticos: novas perspectivas para o campo da reabilitação. Rev. Ter. Ocup. São Paulo, v. 15, n. 3, p. 129-135, 2004.

MÂNGIA, E. F.; RICCI, E. C. "Pensando o Habitar" Trajetórias de usuários de Serviços Residenciais Terapêuticos. Rev. Ter. Ocup. São Paulo, v. 22, n. 2, p. 182-190, 2011. 
MÂNGIA, E. F.; ROSA, C. A. Desinstitucionalização e Serviços Residenciais Terapêuticos. Rev. Ter. Ocup. São Paulo, v. 13, n. 2, p. 71-77, 2002.

MARCOS, C. M. A reinvenção do cotidiano e a clínica possível nos "serviços residenciais terapêuticos”. Psyche. São Paulo, v. 8, n. 15, p. 179-190, 2004.

MARTINS, G. C. S. et al. O processo de implantação de residências terapêuticas em Volta Redonda, Rio de Janeiro. Texto Contexto Enferm. Florianópolis, v. 21, n. 1, p. 86-94, 2012.

MATOS, B. G.; MOREIRA, L. H. O. Serviço residencial terapêutico: o olhar do usuário. Esc. Anna Nery. Rio de Janeiro, v. 17, n. 4, p. 668-676, 2013.

MENEZES, P. et al. Household crowding and compliance with outpatient treatment in patients with non-affective functional psychoses in São Paulo, Brazil. Soc. Psychiatry Psychiatr Epidemiol. v. 35, n. 3, p. 116-120, 2000.

MONTEIRO, C. F. S. et al. O viver e o morar: relaçôes interpessoais de moradores dos serviços residenciais terapêuticos. Rev. Enferm. UERJ. Rio de Janeiro, v. 20, n. esp.1, p. 637-641, 2012.

MOREIRA, M. I. B.; ANDRADE, Â. N. Habitar a cidade: análise de serviços residenciais terapêuticos. Psicol. Soc. Porto Alegre, v. 19, n. 3, p. 46-54, 2007.

NELSON, G. Housing for people with serious mental illness: Approaches, evidence and transformative changes. J. Sociol. Soc. Welf., v. 37, n. 4, p. 123-146, 2010.

PACKER, A. L.; TARDELLI, A. O.; CASTRO, R. C. F. A distribuição do conhecimento científico público em informação, comunicação e informática em saúde indexado nas bases de dados MEDLINE e LILACS. Ciênc. Saúde Colet. Rio de Janeiro, v. 12, n. 3, p. 587-599, 2007. PEREIRA, V. P.; BORENSTEIN, M. S. Iluminando as vivências de mulheres portadoras de transtornos psíquicos e moradoras de uma residência terapêutica. Texto Contexto Enferm. Florianópolis, v. 13, n. 4, p. 527-534, 2004.

PITTA, A. M. F. Um balanço da reforma psiquiátrica brasileira: instituiçóes, atores e políticas. Ciênc Saúde Colet. Rio de Janeiro, v. 16, n. 12, p. 4579-4589, 2011.

PRICE, D. J. S. Little Science, Big Science... And beyond. New York: Columbia University Press, 1986.

RESGALLA, R. M. et al. A Residência Terapêutica: o melhor lugar de se viver. REME. Belo Horizonte, v. 8, n. 2, p. 283-289, 2004.

RIBEIRO NETO, P. M.; AVELLAR, L. Z. Conhecendo os cuidadores de um serviço residencial terapêutico. Mental. Barbacena, v. 7, n. 13, 2009.

. Identidade social e desinstitucionalizaçáo: um estudo sobre uma localidade que recebe residências terapêuticas no Brasil. Saúde Soc. São Paulo, v. 24, n. 1, p. 204-216, 2015. 
. Concepções sobre a interação com moradores de residências terapêuticas. Psicol. Soc. Porto Alegre, v. 28, n. 1, p. 162-170, 2016.

ROMAGNOLI, R.C.etal. Porumaclínica da resistência: experimentaçôesdesinstitucionalizantes em tempos de biopolítica. Interface. Botucatu, v. 13, n. 30, p. 199-207, 2009.

ROTELLI, F.; DE LEONARDIS, O.; MAURI, D. Desinstitucionalização, uma outra via: A Reforma Psiquiátrica Italiana no contexto da Europa Ocidental e dos “países avançados”. In: NICÁCIO, M. F. (Org.). Desinstitucionalização. 2. ed. São Paulo: Hucitec, 2001. p. 17-59.

SANTOS JR., H. P. O.; GUALDA, D. M. R.; SILVEIRA, M. F. A. Similitudes e diferenças nas temáticas que envolvem a moradia e o cuidado nas residências terapêuticas: abordagem qualitativa. Online Braz. J. Nurs. Rio de Janeiro, v. 7, n. 3, 2008. Disponível em: <http:// www.objnursing.uff.br/index.php/nursing/article/view/j.1676-4285.2008.1871/432>. Acesso em: 8 ago. 2018.

- Residências Terapêuticas: uma análise qualitativa secundária sobre o processo de moradia para sofredores psíquicos. Online Braz.J. Nurs. Rio de Janeiro, v. 9, n. 3, 2010. Disponível em: <http://www.objnursing.uff.br/index.php/nursing/article/view/j.1676-4285.2010.3151>. Acesso em: 8 ago. 2018.

SILVA, D.D.; GRÁCIO, M.C.C. Índice h de Hirsch: análise comparativa entre as bases de dados Scopus, Web of Science e Google Acadêmico. Em questão. Porto Alegre, v. 23, p. 196-212, 2017.

SILVA, D. S.; AZEVEDO, D. M. A reforma psiquiátrica na visão de quem cuida: percepçóes de profissionais do serviço residencial terapêutico. Esc. Anna Nery. Rio de Janeiro, v. 15, n. 3, p. 587-594, set. 2011.

SILVA, P.R.F. et al. Desinstitucionalização de pacientes de longa permanência de um hospital psiquiátrico no Rio de Janeiro. Ciênc. Saúde Colet. Rio de Janeiro, v. 22, n. 7, p. 2341-2352, 2017. SILVEIRA, M.F.A.; SANTOS JR., H. P. O. Que eles falem por si: relatos dos profissionais sobre a experiência nas residências terapêuticas. Ciênc. Saúde Colet. Rio de Janeiro, v. 16, n. 4, p. 2089-2098, 2011.

SISKIND, D. et al. A domains-based taxonomy of supported accommodation for people with severe and persistent mental illness. Soc. Psychiatry Psychiatr Epidemiol., v. 48, n. 6, p. 875-894, 2013.

SPRIOLI, N.; COSTA, M.C.S. Cuidar em novo tempo: o trabalho de cuidadores com pacientes psiquiátricos em moradias. Rev. Latinoam. Enferm. Ribeirão Preto, v. 19, n. 5, p. 1155-1162, 2011.

SUIYAMA, R. C. B.; ROLIM, M. A.; COLVERO, L. A. Serviços residenciais terapêuticos em saúde mental: uma proposta que busca resgatar a subjetividade dos sujeitos? Saúde Soc. São Paulo, v. 16, n. 3, p. 102-110, 2007. 
SZTAJNBERG, T. K.; CAVALCANTI, M. T. A arte de morar... na Lua: a construção de um novo espaço de morar frente à mudança do dispositivo asilar para o Serviço Residencial Terapêutico. Rev. Latinoam. Psicopatol. Fundam. São Paulo, v. 13, n. 3, p. 457-468, 2010.

. Sob o pé do castanheiro: histórias que perpassam um Serviço Residencial Terapêutico. Rev. Latinoam. Psicopatol. Fundam. São Paulo, v. 17, n. 2, p. 265-278, 2014.

TENÓRIO, F. A reforma psiquiátrica brasileira, da década de 1980 aos dias atuais: história e conceitos. Hist. Ciênc. Saúde-Manguinhos. Rio de Janeiro, v. 9, n. 1, p. 25-59, 2002.

TORRE, E. H. G.; AMARANTE, P. Protagonismo e subjetividade: a construção coletiva no campo da saúde mental. Ciênc. Saúde Colet. Rio de Janeiro, v. 6, n. 1, p. 73-85, 2001.

VENTURINI, E. O caminho dos cantos: morar e intersetorialidade na saúde mental. Fractal: Revista de Psicologia. Niterói, v. 22, n. 3, p. 471-480, 2010.

VIDAL, C. E. L.; BANDEIRA, M.; GONTIJO, E. D. Reforma psiquiátrica e serviços residenciais terapêuticos. J Bras. Psiquiatr. Rio de Janeiro, v. 57, n. 1, p. 70-79, 2008.

WACHS, F. et al. Processos de subjetivação e territórios de vida: o trabalho de transição do hospital psiquiátrico para serviços residenciais terapêuticos. Physis. Rio de Janeiro, v. 20, n. 3, p. 895-912, 2010.

WORLD HEALTH ORGANIZATION. Transition from hospital to community: a literature review on housing. Geneva: World Health Organization, 1993.

\section{Nota}

${ }^{1}$ W. Y. Oda e A. P. Carvalho: concepção do projeto, aquisição, análise e interpretação dos dados, redação e revisão crítica do artigo, aprovaçáo da versão final a ser publicada. C. M. Hilário: concepção do projeto, análise dos dados, redação e revisão crítica do artigo, aprovação da versão final a ser publicada. J. P. Furtado: concepçáo do projeto, análise e interpretação dos dados, redação e revisão crítica do artigo, aprovação da versão final a ser publicada. Este texto é resultado de dissertação de mestrado. 


\section{Abstract}

Expand reflections and alternatives: analysis of housing for people with severe mental disorder in Brazil

Based on the assumption that there would be a certain correspondence in the theoretical plan to the numerical and qualitative stagnation of housing options and offers aimed at people with severe mental disorders in Brazil, we analyzed, through bibliographic review and bibliometrics, how the topic has been addressed in publications national indexed in the Lilacs and Scopus databases, between the years 2000 and 2017. We found that the Brazilian regional distribution of the authors is uneven, and the scientific production is still numerically limited, predominantly descriptive and focused on work and support processes. The methodological designs vary little, and the theoretical references are derived from seminal texts that supported the beginning of the Brazilian psychiatric reform. We understand that the findings of this study allow us to confirm the initial assumption that the debate about housing for people with severe mental disorders lacks new theoretical and methodological approaches, contrary to what is indicated by recently released regulations by the Ministry of Health in this regard.

> Keywords: deinstitutionalization; mental health; housing; bibliometric indicators. 